\title{
The Necessity of Paying More Attention to the Neurological and Psychological Problems Caused by COVID-19 Pandemic During Pregnancy
}

\author{
Seyed Mehdi Haghdoost ${ }^{1}$, Mehdi Khanbabayi Gol ${ }^{2^{*}(\mathbb{D}}$
}

A fter two epidemics of the severe acute respiratory syndrome (SARS) and Middle-East respiratory syndrome (MERS) with mortality rates of 105 and 344 per 1000 individuals, respectively (1), coronavirus disease 2019 (COVID-19) was discovered late in 2019 in China and spread swiftly around the world (2). Pneumonia caused by COVID-19 is a highly contagious infection with several routes of transmission, and its ongoing outbreak is considered as a global health emergency by the World Health Organization $(3,4)$.

The COVID-19 is transmitted through airborne droplets and particles and physical contact and affects all age groups at risk. The risk factors of the disease include a history of lung disease, infectious disease, heart disease, or immunodeficiency, cancer, undergoing chemotherapy and radiotherapy, old age, obesity, and pregnancy (5).

In the outbreaks of infectious diseases, pregnant women and their fetuses are at high risk. Pregnant women are more susceptible to infectious diseases than the general population, particularly to respiratory diseases and severe pneumonia, because they have low immune systems, their estrogen and progesterone levels are extraordinarily high in the upper respiratory tract, and the lung capacity is low. Also, physiological changes for adaptation to pregnancy (i.e., diaphragmatic elevation, increased oxygen demand, respiratory tract mucosal oedema) cause sensitivity to hypoxia. The potential risks of a cytokine storm due to infection in pregnant women may be associated with severe complications and even death (6-8).

Although COVID-19 is known as an acute respiratory syndrome, it is recently confirmed that in addition to respiratory symptoms, about $36 \%$ of patients with COVID-19 also manifest neurological symptoms such as headache, confusion, and paresthesia, which their prevalence is higher in severe cases compared to mild or moderate ones (9). During epidemics, such as COVID-19, fear of disease and death, along with the turmoil of daily living activities, put people at risk of COVID-19-related

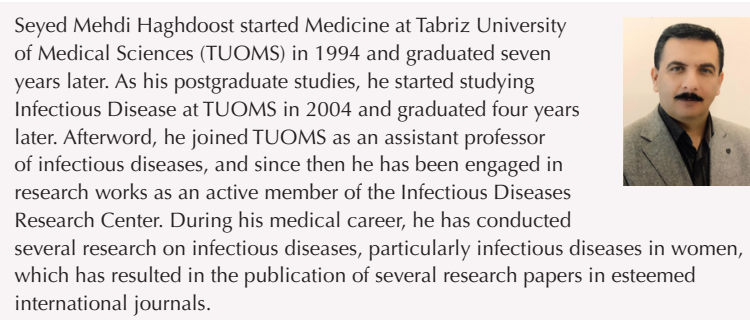

Seyed Mehdi Haghdoost started Medicine at Tabriz University of Medical Sciences (TUOMS) in 1994 and graduated seven years later. As his postgraduate studies, he started studying Infectious Disease at TUOMS in 2004 and graduated four years later. Afterword, he joined TUOMS as an assistant professor of infectious diseases, and since then he has been engaged in research works as an active member of the Infectious Diseases Research Center. During his medical career, he has conducted several research on infectious diseases, particularly infectious diseases in women, which has resulted in the publication of several research papers in esteemed international journals.

anxiety. Anxious about COVID-19 is common, and it seems that in large part is because of the unknown nature of the virus that leads to cognition ambiguity in people. Fear of unknowns reduces immune perception and causes anxiety. Due to the unknown nature of the virus, scientific knowledge of COVID-19 is very little, which intensifies anxiety about the disease. People under such circumstances seek more information to relieve their anxiety (10).

Since COVID-19 infection can affect the nervous system and subsequently, the cognition of the patient, it is believed that the virus, in coordination with the immune system, turns the condition into a persistent infection and causes neurological complications. It should be noted that COVID-19 may alter fetal-maternal immune responses and affect the well-being of the mother and infant, and since pregnant women are at high risk of the disease, it can cause many problems to them and affect the process of pregnancy, labor, and postpartum, and involve the mother in different complications for a long time and cause irreparable damage to women's public health. Therefore, it is necessary to pay more attention to the neurological and psychological problems of pregnant women during the COVID-19 epidemic.

Ethical Issues

Not applicable.

Conflict of Interests

None. 


\section{References}

1. Di Mascio D, Khalil A, Saccone G, et al. Outcome of Coronavirus spectrum infections (SARS, MERS, COVID 1-19) during pregnancy: a systematic review and meta-analysis. Am J Obstet Gynecol. 2020;2(2):100107. doi:10.1016/j. ajogmf.2020.100107.

2. Chen H, Guo J, Wang C, et al. Clinical characteristics and intrauterine vertical transmission potential of COVID-19 infection in nine pregnant women: a retrospective review of medical records. Lancet. 2020;395(10226):809-15. doi:10.1016/S0140-6736 (20) 30360.

3. Huang C, Wang Y, Li X, et al. Clinical features of patients infected with 2019 novel coronavirus in Wuhan, China. The lancet. 2020;395(10223):497-506. doi:10.1016/S01406736(20)30183-5.

4. Wang C, Horby PW, Hayden FG, Gao GF. A novel coronavirus outbreak of global health concern. Lancet. 2020;395(10223):470-3. doi:10.1016/S0140-6736(20)301859.

5. Weiss $P$, Murdoch DR. Clinical course and mortality risk of severe COVID-19. Lancet. 2020;395(10229):1014-5.
doi:10.1016/S0140-6736(20)30633-4.

6. Liu H, Wang L-L, Zhao S-J, Kwak-Kim J, Mor G, Liao A-H. Why are pregnant women susceptible to viral infection: an immunological viewpoint? J Reprod Immunol. 2020;2020:103122. doi:10.1016/j.jri.2020:103122.

7. Liang H, Acharya G. Novel corona virus disease (COVID-19) in pregnancy: What clinical recommendations to follow? Acta Obstet Gynecol Scand. 2020;99(4):439-42. doi:10.1111/ aogs.13836.

8. Kurdoğlu M, Khaki A. What Is the Current State of Knowledge About the Novel Coronavirus Infection During Pregnancy? Int J Womens Health Reprod Sci. 2020;8(2):110-1. doi:10.15296/ ijwhr.2020.17.

9. Wu Y, Xu X, Chen Z, et al. Nervous system involvement after infection with COVID-19 and other coronaviruses. Brain Behav Immun. 2020;8:18-22. doi:10.1016/j.bbi.2020.03.031.

10. Alipour A, Ghadami A, Alipour Z, Abdollahzadeh H. Preliminary validation of the Corona Disease Anxiety Scale (CDAS) in the Iranian sample. Quarterly Journal of Health Psychology. 2020;8(32):163-75. doi:10.30473/ hpj.2020.52023.4756.

(C) 2020 The Author(s); This is an open-access article distributed under the terms of the Creative Commons Attribution License (http:// creativecommons.org/licenses/by/4.0), which permits unrestricted use, distribution, and reproduction in any medium, provided the original work is properly cited. 